\title{
Correction to: The impact of EU and non-EU immigration on British wages
}

\author{
Stephen Nickell ${ }^{1}$ and Jumana Saleheen ${ }^{2^{*}}$ (D)
}

* Correspondence:

Jumana.saleheen@bankofengland.co.uk

${ }^{2}$ Bank of England, Threadneedle

Street, London EC2R 8AH, UK

\section{Correction to: IZA journal of development and migration (2017) 7:15} DOI: 10.1186/s40176-017-0096-0

The original version of this article (Nickell \& Saleheen, 2017), published on 11 October 2017, contains an error in the "Country of Birth" section of Appendix 1. In this Correction the incorrect and correct version of the affected sentence is shown. The error and corrected error are in bold.

The sentence was originally provided like this:

- We consider $\mathbf{2 5}$ counties and country groups of birth.

The correct sentence should read:

- We consider 52 counties (or country groups) of birth.

\section{Author details}

${ }^{1}$ Honorary Fellow, Nuffield College Oxford, Oxford, UK. ${ }^{2}$ Bank of England, Threadneedle Street, London EC2R 8AH, UK.

Received: 17 October 2017 Accepted: 17 October 2017

Published online: 22 November 2017

\section{Reference}

Nickell S, Saleheen J. The impact of EU and non-EU immigration on British wages. IZA J Dev Migr. 2017;7:15 doi: 10.1186/s40176-017-0096-0. 